\title{
Improvement of Immersion into a Virtual Game World: Using "Real Robot" as a Player Character
}

\author{
Tao MORISAKI ${ }^{\mathrm{a},}{ }^{*}$, Shohei MIYABARA ${ }^{\mathrm{a}}$, Naohiro KOSHIJI ${ }^{\mathrm{b}}$ \\ ${ }^{a}$ National Institute of Technology, Kurume College, Advanced Engineering School, Komorino Kurume 1-1-1, \\ Fukuoka-ken 830-8555, JAPAN \\ ${ }^{\mathrm{b}}$ National Institute of Technology, Kurume College, Komorino Kurume 1-1-1, Fukuoka-ken 830-8555, JAPAN
}

*Corresponding Author: taomorisaki@gmail.com

\begin{abstract}
Immersion is an important sense for a virtual game world. Moreover, Virtual Reality (VR) is an effective method to improve immersion. However, VR requires wearing some devices such as a goggle which can be cumbersome of users. Therefore, an alternative method to improve immersion other than VR is proposed. In this study, the authors propose using a real robot as the player's character. At this stage, the authors developed a game for experiment called "Catch Apple" in which players can use a real robot. The authors then surveyed 39 research subjects regarding the effect using a real robot had on them. The data was processed using Factor Analysis in order to find factors relating to immersion. The authors compared their factor scores. The results show that the factor scores of the "Real Robot" were significantly greater than the factor scores of the "Virtual Robot" ( $p<$ $0.05)$. In the future, the authors will develop new games and conduct similar experiments to confirm the correctness of the factors relating to immersion.
\end{abstract}

Keywords: immersion, robot, virtual reality, game, virtual world.

\section{Introduction}

Recently, many virtual world games have been commercially released. Immersion is an important element of these games ${ }^{(1)}$, and using Virtual Reality (VR) is an effective method to improve it. In addition to gaming, VR is used for medical therapy ${ }^{(2)}$. Using VR, patients are rehabilitated in each suitable virtual world. Thus, much research is undertaken to improve immersion ${ }^{(3)-(4)}$. However, VR requires wearing devices which are oftentimes have noxious aspects ${ }^{(5)}$. Therefore, the authors propose a method to improve immersion in a virtual world game without the use of VR. The method is the materialization of a virtual player character, in other words, using a real robot to act as a player's character. At this stage, the authors have developed a computer game system to realize this method and have evaluated the abilities of this system. This paper provides validation of our method of improving immersion.

\section{Development of A Game for Experiment}

\subsection{Foundation of A Game}

For this study, the authors developed and used a computer game system called "Catch Apple". The opening scene of "Catch Apple" is illustrated in Fig. 1. In "Catch Apple", images of apples fall from the upper part of the computer display, and players aim to get ten of them in 20 seconds. To start the game, players choose either "Real Robot" or "Virtual Robot" for their player character. "Real Robot" and "Virtual Robot" are shown in Fig. 2.

The "Real robot" is simply constituted, having two wheels, a ball caster, two arms, an active speaker and a web camera (although this study doesn't use the web camera). The wheels and ball caster correspond to the character's feet.

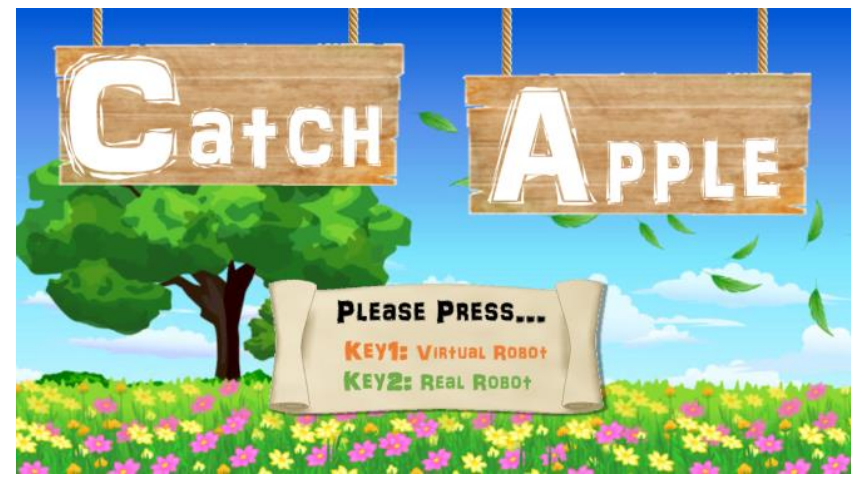

Fig. 1 Opening scene of "Catch Apple" 


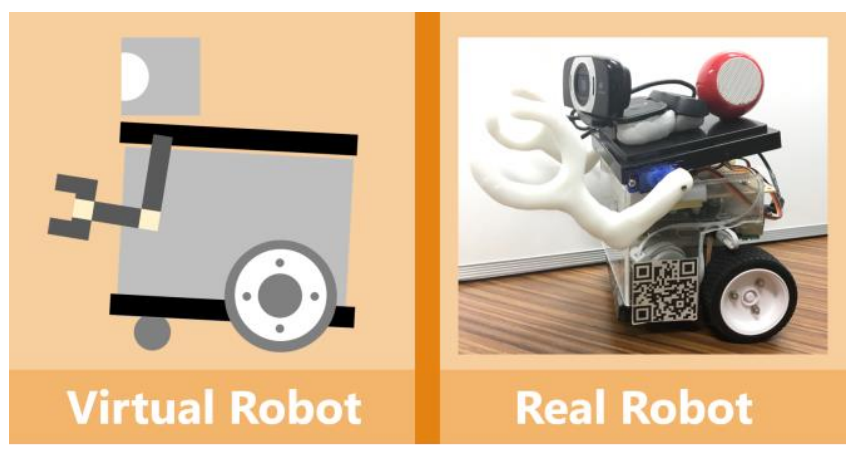

Fig. 2 "Virtual Robot" and "Real Robot"

Two arms are moved by servo motors, and all the robot's devices are controlled by Raspberry Pi 3. Moreover, "Real Robot" is similar to "Virtual Robot" in appearance.

\subsection{Case of "Virtual Robot"}

A game scene is shown in Fig. 3, and a flow of the game in this case is as follows (illustrated in Fig. 4): 1) The game starts after three counts; 2) The apples fall from above; 3) In order for a player to "get" an apple, the "Virtual Robot" must touch it. "Virtual Robot", which moves only left or right, is controlled by using the left and right arrow keys on the computer keyboard; 4) After getting an apple, "Virtual Robot" waves its arms jubilantly while an audio cheer "Yattazo!" -Japanese for "I got it!" -- plays in the background; 5) If a player gets 10 apples in 20 seconds, the game shows victorious scene for the winner. If a player fails, this game shows a scene for the loser.

\subsection{Case of "Real Robot}

In this case, players "get" an apple when "Real Robot" overlaps the apple on the screen. Therefore, it is necessary to detect the horizontal position of "Real Robot" in the real world and convert it into the position in the virtual world in the game. The authors do this by putting a QR code on "Real Robot" and detecting it using a web camera. "Catch Apple" receives the center position and converts it into the corresponding position in the game world. A picture of playing this game is shown in Fig. 5.

The detection system hardware consists of a Windows 10 computer and a web camera. A breakdown of the process is as follows: 1) The web camera takes a picture of "Real Robot"; 2) The computer detects the position of the four corners of the QR code in this picture and finds the center position by calculating the average of the 4 positions; 3) "Catch Apple" receives the center position and converts it into the position in the game world through the following expression:

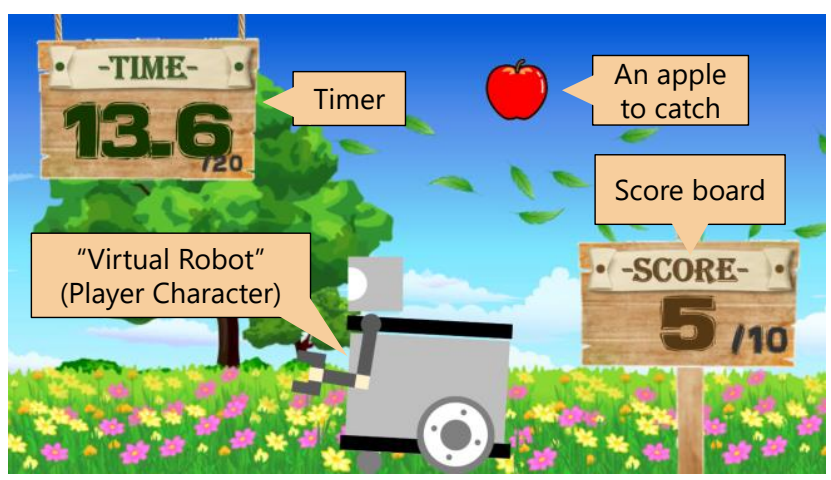

Fig. 3 Playing scene
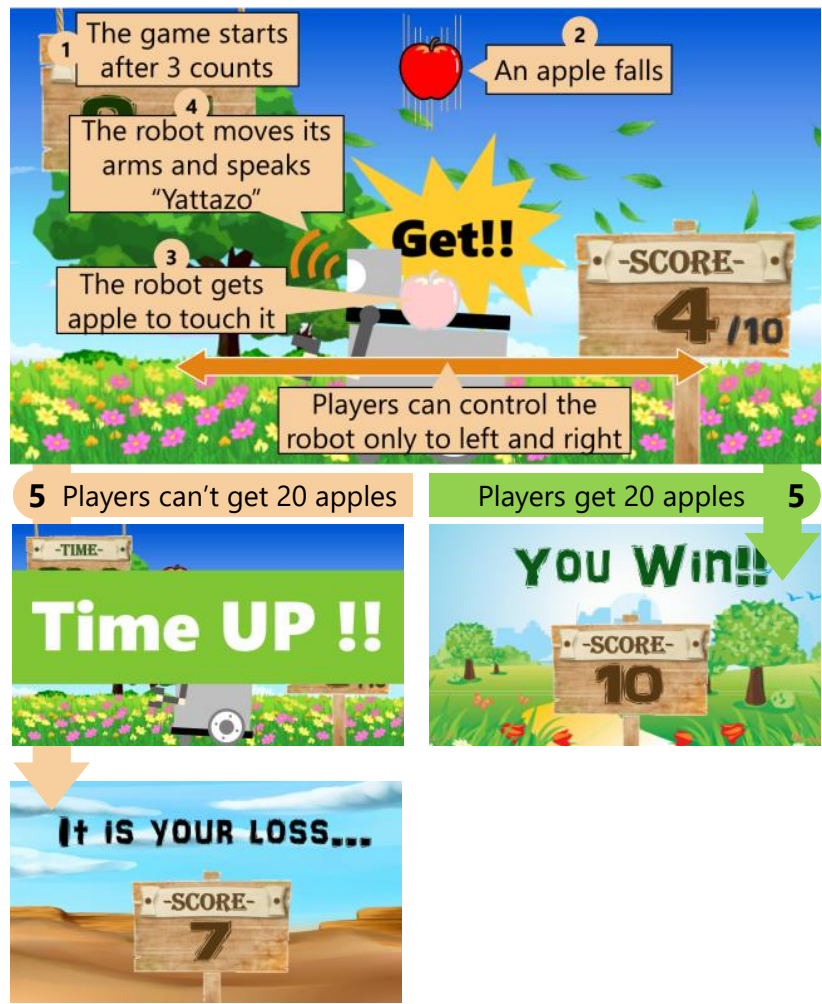

Fig. 4 Flow of the game in case of "Virtual Robot"

$$
x 3=\frac{(x 2-x 1)(X 3-X 1)}{X 2-X 1}+x 1
$$

where $x 1, x 2$ and $x 3$ are respectively left end position, right end position and the position of the transparent game object in the game world. Moreover, $X 1, X 2$ and $X 3$ are respectively left end position, right end position and the center position of QR code in the picture. This is illustrated in Fig. 6. $x 1$ and $x 2$ had been previously confirmed in the development environment (In this study, the authors used Unity). $X 1$ and $X 2$ are previously measured by processing pictures of which there is QR code at left and right end.

A flow of the game in this case is as follows: 1) The game starts with a message showing "Waiting ..." until the web camera detects the QR code. When detected, a 3-second timer starts after which the game immediately begins; 2) 


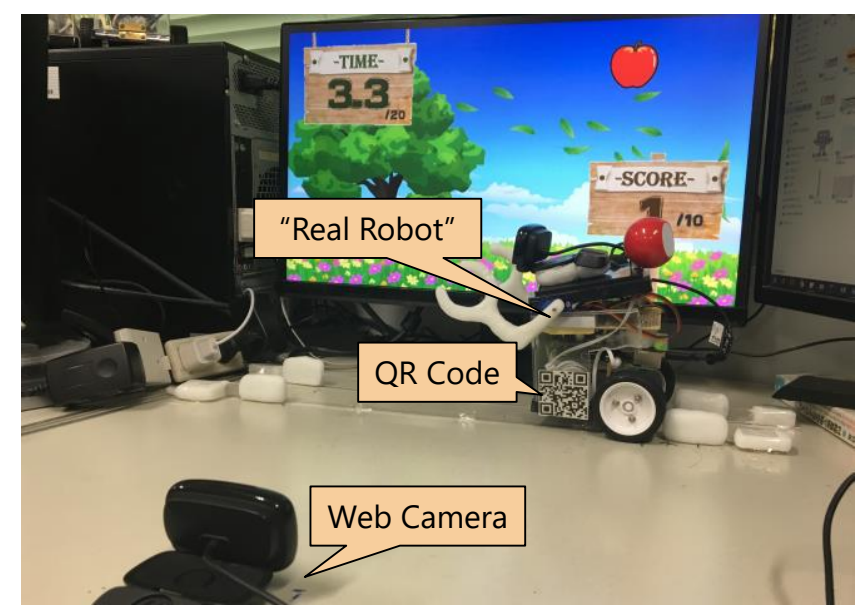

Fig. 5 Picture of playing game

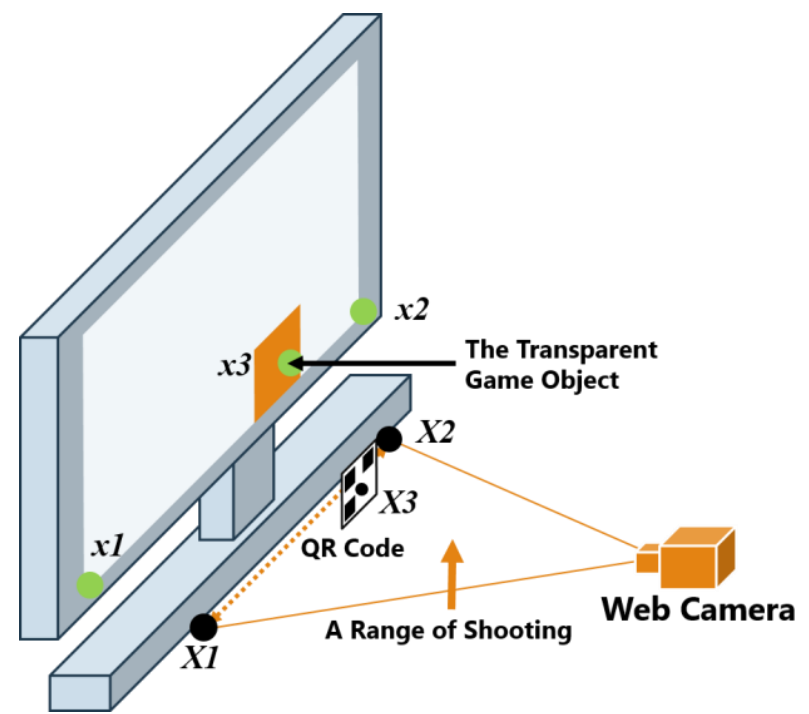

Fig. 6 Description of each coordinate

Apples begin falling from above; 3) The player controls "Real Robot" by using the same method of "Virtual Robot"; 4) A transparent game object which is formed to match the size of "Real Robot" moves to the position where the QR code is detected. In other words, this game object tracks the horizontal motion of "Real Robot"; 5) When the game object touches an apple, the player "gets" the apple; 6) The computer sends information via Wi-Fi every time an apple is "got". Corresponding to a "got", "Real Robot" plays the sound of "Yattazo!" from its speaker while waving its arms; 7) The rest is the same as 5) in the case of "Virtual Robot".

\section{Experiment}

\subsection{Method}

Our research design was to use a Semantic Differential questionnaire to confirm the effects of "Real Robot" in "Catch Apple". The authors used 26 two-polar adjectives
Table 126 two polar adjectives

\begin{tabular}{|c|c|c|c|c|}
\hline No. & Japanese & English & Japanese & English \\
\hline 1 & 好きな & favourite & きらいな & diskikeable \\
\hline 2 & 親しみやすい & friendly & 親しみにくい & unfriendly \\
\hline 3 & 感じのいい & decent & 感じの悪い & rude \\
\hline 4 & 分かりやすい & easy & 分かりにくい & difficult \\
\hline 5 & 単純な & simple & 複雑な & complex \\
\hline 6 & 早い & early & 遅い & late \\
\hline 7 & すばやい & quick & 鈍い & slow \\
\hline 8 & 楽しい & fun & つまらない & boring \\
\hline 9 & 充実した & fulfilling & 空虚な & emptiness \\
\hline 10 & 達成感のある & satisfying & 達成感のない & unsatisfying \\
\hline 11 & 手応えのある & tough & 物足りない & unsatisfactory \\
\hline 12 & きれいな & clean & 污い & dirty \\
\hline 13 & かわいい & pretty & 憎らしい & detestable \\
\hline 14 & 癒しのある & soothing & 落ち着かない & restless \\
\hline 15 & 続けたい & want to continue & 辞めたい & want to quit \\
\hline 16 & 興味深い & intresting & 退屈な & uninteresting \\
\hline 17 & 集中した & focussed & 貴の散った & distracted \\
\hline 18 & 暖かい & warm & 冷たい & cold \\
\hline 19 & 打ち解けた & casual & 堅苦しい & serious \\
\hline 20 & 近づきやすい & approachable & 近づきがたい & unapproachable \\
\hline 21 & 派手な & gorgeous & 地味な & plain \\
\hline 22 & 明るい & cheerful & 暗い & gloomy \\
\hline 23 & 優しい & kind & 怖い & scary \\
\hline 24 & 賢い & wize & 愚かな & foolish \\
\hline 25 & 積極的な & aggressive & 消極的な & passive \\
\hline 26 & なさそうな & novel & ありがちな & common \\
\hline
\end{tabular}

which were decided according to Brown's study ${ }^{(1)}$. They are shown in Table 1. However, this questionnaire was conducted in the Japanese language. The list of adjectives translated from Japanese into English is shown in Table 1.

The adjectives are rated by 7 -grade evaluation. Brown says "immersion is indeed used to describe the degree of involvement" and proposes that involvement is divided into three levels: 1) Engagement; 2) Engrossment; and 3) Total Immersion. Moreover, Brown proposed that each level has some barriers. The authors conjecture that immersion can be evaluated by using them. Therefore, the adjectives are defined according to those barriers. This relationship is shown in Table 2. However, it may be novel to control "Real Robot" for most people which could affect their questionnaire response. Therefore, "Novel" was added to these adjectives to survey its effects.

In this study, 39 students in National Institute of Technology, Kurume Courage (NITKC) are selected as research subjects. "Catch Apple" has two modes. Firstly, a research subject selects and plays one of the two modes and immediately afterwards answers questions related to that mode. After this, the research subject plays the other mode and follows up by answering its corresponding questions. The answered questionnaires are processed by Factor Analysis. Then, the results for each mode are compared with 


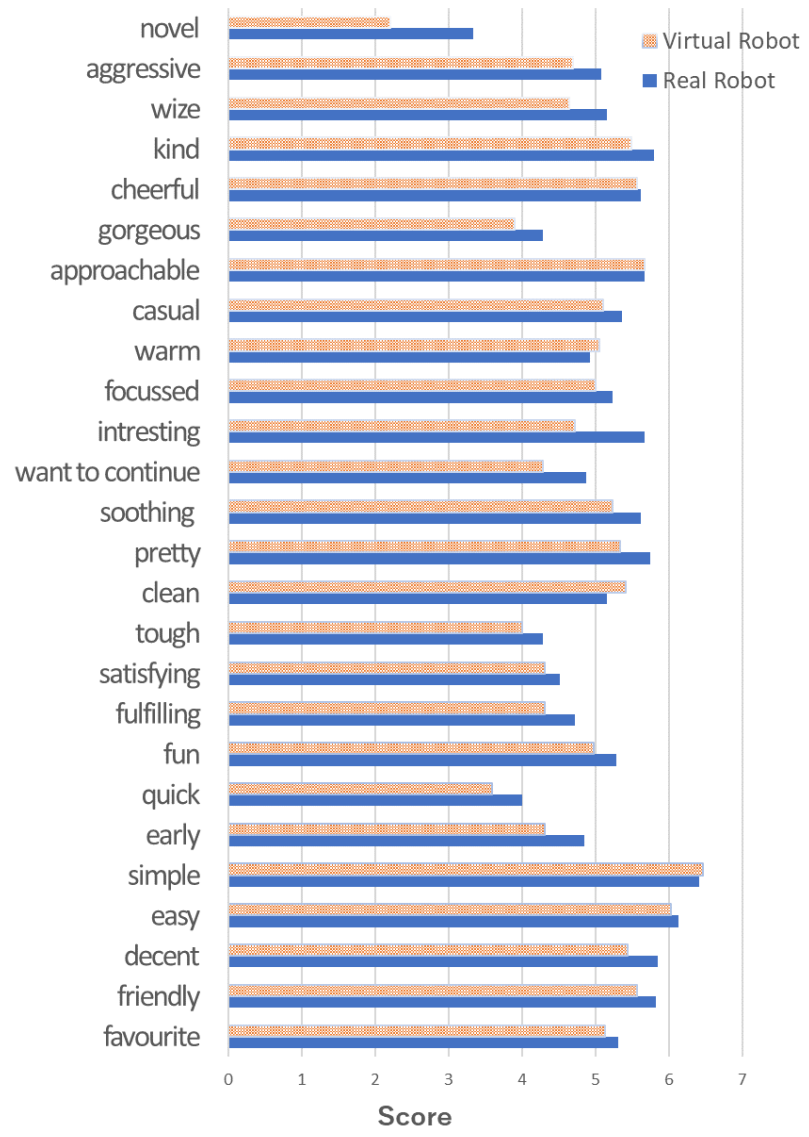

Fig. 7 Result of the questionnaires

each other. The method is referred to Kanda's study ${ }^{(6)}$. Kanda evaluated interactions between a robot and human.

\subsection{Result and Discussion}

Results of the questionnaires are shown in Fig. 7. This is average of scores. Firstly, the authors evaluated this data by Wilcoxon signed-rank test which showed that that the scores of "Real Robot" are significantly greater than the scores of "Virtual Robot" $(p<0.05)$. Moreover, the 26 twopolar adjectives are defined according to three levels of involvement. Therefore, scores should rise in the order of Engagement, Engrossment, and Total Immersion. However, the scores didn't reflect this (Fig. 7). The reason may be that the determinations of the adjectives was mistaken. Therefore, the authors confirmed the validity of the polar adjectives and reclassified them into three levels after Factor Analysis.

Secondly, the authors processed the results of the questionnaires by Factor Analysis in order to find factors relating to immersion and to evaluate them. The authors found 9 factors by chi-square test, and its loadings are shown in Table 3. The authors evaluated the average of the factor scores by Wilcoxon signed-rank test. This evaluation shows that factor scores of "Real Robot" are significantly greater than the factor scores of "Virtual Robot" $(p<0.05)$. The
Table 2 Relationship between Levels and adjectives

\begin{tabular}{|c|c|c|c|}
\hline \multirow{2}{*}{ Levels } & \multirow{2}{*}{ Barriers } & \multicolumn{2}{|r|}{ Adjectives } \\
\hline & & No. & Name \\
\hline \multirow{11}{*}{ Engagement } & \multirow{3}{*}{ Preference } & 1 & favourite \\
\hline & & 2 & friendly \\
\hline & & 3 & decent \\
\hline & \multirow{4}{*}{ Easy of use } & 4 & easy \\
\hline & & 5 & simple \\
\hline & & 6 & early \\
\hline & & 7 & quick \\
\hline & \multirow{4}{*}{ Rewards } & 8 & fun \\
\hline & & 9 & fulfilling \\
\hline & & 10 & satisfying \\
\hline & & 11 & tough \\
\hline \multirow{6}{*}{ Engrossment } & \multirow{3}{*}{ Visual } & 12 & clean \\
\hline & & 13 & pretty \\
\hline & & 14 & soothing \\
\hline & \multirow{2}{*}{ Want to continue } & 15 & want to continue \\
\hline & & 16 & intresting \\
\hline & Intention & 17 & focussed \\
\hline \multirow{8}{*}{$\begin{array}{c}\text { Total } \\
\text { Immersion }\end{array}$} & \multirow{3}{*}{ Empathy } & 18 & warm \\
\hline & & 19 & casual \\
\hline & & 20 & approachable \\
\hline & \multirow{5}{*}{ Atmosphere } & 21 & gorgeous \\
\hline & & 22 & cheerful \\
\hline & & 23 & kind \\
\hline & & 24 & wize \\
\hline & & 25 & aggressive \\
\hline
\end{tabular}

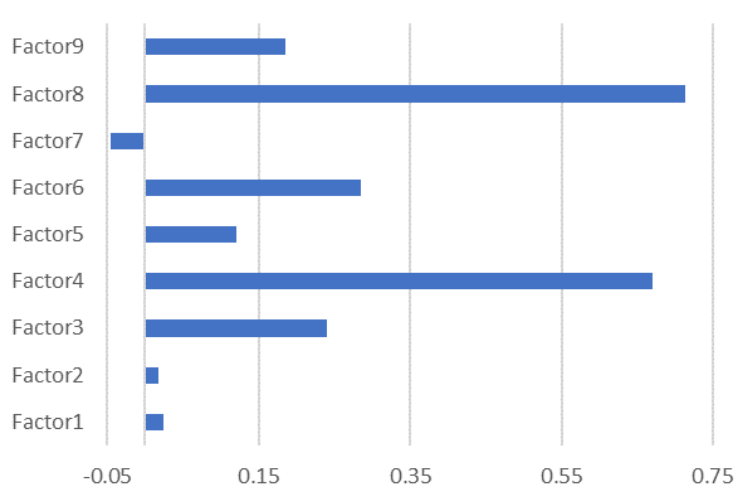

Fig. 8 Difference of Factor Score

authors subtracted factor score of "Virtual Robot" from factor score of "Real Robot". The result is shown in Fig. 8.

Thirdly, the authors classified the factors into Engagement, Engrossment and Total Immersion by using only loadings greater than or equal to 0.5 . Factor 1 affects adjective 2(A2), 3, 12, 13, 14, 17, 18, and 19. However, A18 and A19 is similar to A2, A3. Therefore, A18 and A19 did same work as A2 and A3. Tus Factor1 was classified into Engagement and Engrossment. Factor2 affects A9, A10 and A11, thus was classified into Engagement. Factor3 affects 
Table 3 Loadings

\begin{tabular}{|c|c|c|c|c|c|c|c|c|c|c|c|}
\hline No. & Adjectives & Factor1 & Factor2 & \begin{tabular}{|l|} 
Factor3 \\
\end{tabular} & Factor 4 & Factor5 & Factor6 & Factor7 & Factor8 & \begin{tabular}{|l|} 
Factor9 \\
\end{tabular} & Communality \\
\hline 1 & favourite & 0.259 & 0.185 & \begin{tabular}{|l|}
0.699 \\
\end{tabular} & 0.119 & 0.085 & 0.099 & 0.141 & 0.045 & 0.177 & 0.675 \\
\hline 2 & friendly & 0.771 & 0.186 & 0.194 & 0.094 & 0.109 & -0.012 & 0.217 & 0.046 & -0.006 & 0.737 \\
\hline 3 & decent & 0.705 & 0.089 & 0.291 & 0.148 & 0.347 & 0.147 & 0.080 & 0.140 & 0.113 & 0.793 \\
\hline 4 & easy & 0.194 & 0.075 & 0.306 & 0.086 & 0.145 & 0.105 & 0.539 & -0.320 & 0.145 & 0.590 \\
\hline 5 & simple & 0.211 & 0.061 & 0.089 & -0.030 & 0.162 & 0.014 & 0.950 & -0.089 & 0.047 & 0.995 \\
\hline 6 & early & 0.277 & -0.048 & 0.056 & 0.063 & 0.133 & 0.931 & 0.127 & 0.025 & -0.083 & 0.995 \\
\hline 7 & quick & 0.055 & 0.012 & 0.095 & 0.156 & 0.082 & 0.619 & -0.044 & 0.059 & 0.184 & 0.465 \\
\hline 8 & fun & 0.116 & 0.419 & 0.870 & 0.135 & 0.021 & 0.119 & 0.093 & -0.087 & -0.022 & 0.995 \\
\hline 9 & fulfilling & 0.061 & 0.692 & 0.456 & 0.129 & 0.042 & 0.025 & 0.040 & -0.005 & -0.104 & 0.722 \\
\hline 10 & satisfying & 0.217 & 0.857 & 0.092 & 0.040 & -0.080 & -0.096 & 0.055 & 0.160 & 0.032 & 0.837 \\
\hline 11 & tough & 0.245 & 0.713 & 0.206 & 0.201 & -0.088 & -0.011 & -0.009 & -0.019 & 0.006 & 0.660 \\
\hline 12 & clean & 0.588 & 0.058 & 0.099 & 0.081 & 0.079 & 0.181 & 0.104 & -0.068 & 0.209 & 0.464 \\
\hline 13 & pretty & 0.595 & -0.008 & 0.133 & 0.151 & 0.129 & 0.145 & 0.167 & 0.057 & 0.542 & 0.757 \\
\hline 14 & soothing & 0.543 & -0.023 & 0.085 & 0.088 & 0.179 & 0.142 & 0.102 & -0.001 & 0.789 & 0.995 \\
\hline 15 & want to continue & 0.315 & 0.396 & 0.458 & 0.449 & -0.051 & 0.020 & 0.196 & 0.130 & -0.022 & 0.726 \\
\hline 16 & intresting & 0.161 & 0.294 & 0.052 & 0.634 & 0.143 & 0.2 & 0.2 & 0.2 & 0.178 & 0.720 \\
\hline 17 & focussed & 0.584 & 0.291 & 0.216 & 0.224 & 0.048 & 0.089 & 0.078 & -0.145 & -0.007 & 0.560 \\
\hline 18 & warm & 0.695 & 0.072 & -0.163 & -0.057 & 0.158 & 0.056 & -0.066 & -0.150 & 0.208 & 0.616 \\
\hline 19 & casual & 0.664 & 0.207 & 0.152 & 0.155 & 0.205 & 0.065 & 0.137 & -0.056 & 0.008 & 0.599 \\
\hline 20 & approachable & 0.208 & -0.061 & 0.275 & 0.295 & 0.273 & -0.016 & 0.134 & -0.496 & 0.183 & 0.582 \\
\hline 21 & gorgeous & -0.020 & 3 & 8 & .227 & 0.3 & 0.2 & 0.0 & 0.0 & 9 & 0. \\
\hline 22 & cheerful & 0.320 & 0.058 & 0.071 & 0.120 & 0.736 & 0.095 & 0.102 & -0.080 & 0.131 & 0.710 \\
\hline 23 & kind & 0.298 & -0.182 & 0.003 & 0.074 & 0.732 & 0.130 & 0.145 & -0.014 & 0.020 & 0. \\
\hline 24 & wize & 0.035 & 0.040 & 0.134 & 0.597 & 0.067 & 0.048 & -0.109 & 0.001 & 0.065 & 0.401 \\
\hline 25 & aggressive & 0.307 & 0.286 & 0.033 & 0.565 & 0.114 & 0.159 & 0.087 & -0.156 & -0.108 & 0.578 \\
\hline 26 & novel & -0.031 & 0.106 & 0.080 & 0.121 & 0.034 & 0.093 & -0.125 & 0.852 & 0.080 & 0.791 \\
\hline c & contribution & 16.008 & 10.208 & 8.4273 & 6.631 & 6.371 & 6.1155 & 5.9549 & 4.9994 & 4.7911 & \\
\hline \multicolumn{2}{|c|}{ cumulative contribution } & 16.008 & 26.215 & 34.643 & 41.274 & 47.645 & 53.76 & 59.715 & 64.7147 & 69.506 & \\
\hline
\end{tabular}

Table 4 Result of classification

\begin{tabular}{|c|l|}
\hline \multirow{4}{*}{ Levels } & Factors \\
\hline \multirow{4}{*}{ Engagement } & Factor1 \\
\cline { 2 - 2 } & Factor2 \\
\cline { 2 - 2 } & Factor3 \\
\cline { 2 - 2 } & Factor6 \\
\cline { 2 - 2 } Engrossment & Factor7 \\
\cline { 2 - 2 } & Factor1 \\
\cline { 2 - 2 } & Factor4 \\
\hline \multirow{2}{*}{ Total Immersion } & Factor9 \\
\cline { 2 - 2 } & Factor4 \\
\hline \multirow{2}{*}{ none } & Factor5 \\
\hline
\end{tabular}

A1 and A8, thus was classified into Engagement. Factor4 affects A16, A24 and A25, thus was classified into Engrossment and Total Immersion. Factor5 affects A22 and A23, thus was classified into Engagement. Factor6 affects A6 and A7, thus was classified into Engagement. Factor7 affects A4 and A5, thus was classified into Engagement. Factor8 affects only A26. A26 is the additional adjective and doesn't relate to immersion. Therefore, Factor8 may not relate to immersion. Moreover, "Novel" doesn't affects result of this experiment."Factor9 affects A13 and A14, thus was classified into Engrossment. This resulting classification is shown in Table 4. The result shows that the factors classified into Engagement are a majority. However, there were no factors classified into Total Immersion. The reason for this is that Engagement is the lowest level and Total 
immersion is the highest level. Therefore, the authors conjecture that the classification is correct. Moreover, players couldn't reach Total Immersion when they played "Catch Apple".

Lastly, the authors evaluated the scores of factors relating to immersion by Wilcoxon signed-rank test. The results show that the factor scores of "Real Robot" are significantly greater than the factor scores of "Virtual Robot" $(\mathrm{p}<0.05)$. Therefore, the authors conjecture that using "Real Robot" as a player character improves immersion of games.

\section{Conclusions}

In this paper, the authors verified a method to improve immersion into games. Firstly, the authors developed the game "Catch Apple" in which a player can use "Real Robot" as a player character. The game is shown in Fig. 1 and Fig. 3 and "Real Robot" in Fig. 2. Secondly, the authors designed a questionnaire based on Brown's study of immersion $^{(1)}$ and administered it to 39 students at NITKC. The adjectives tested in the questionnaire are shown in Table 1 and the results in Fig. 7. Thirdly, the authors processed the survey responses using Factor Analysis in order to find factors relating to immersion. The resulting factors are shown in Table 4. Fourthly, the authors evaluated the resulting factors. The results show that the factor scores of "Real Robot" is significantly greater than the factor scores of "Virtual Robot" $(\mathrm{p}<0.05)$. Lastly, the authors conjecture that using "Real Robot" as player character improves the sensation of immersion of games.

However, there are fore problems. Firstly, the research subjects are few to implement Factor Analysis. Moreover, they belong to the same group. Secondly, the authors found the factors relating to immersion instinctively. Therefore, the correctness of the founded factors is not certain. Thirdly, the players couldn't reach Total Immersion. One reason may be that players may not like the game "Catch Apple" because the authors developed it only for the experiment. Because of this, the authors may not find all factors relating immersion. Fourthly, if players look the computer display from except the front, players may not able to play correctly the game using "Real Robot" as a player's character. Because, in this case, players can't recognize correctly location relationship between "Real Robot" and apple in the virtual game world. Generally, players look the computer display from the front. However, this restriction may have bad influences on immersion.

Therefore, the authors will follow-up with three tasks:
Firstly, the authors will develop a new game which reference existing popular games such as air hockey in order to be liked by players. Secondly, the authors will conduct similar research on the new game in order to confirm the correctness of the factors relating to immersion. Thirdly, the authors will survey influence of changes of player's viewpoint on immersion.

\section{Acknowledgment}

The authors are grateful to 39 students of NITKC who cooperated the experiment in this paper.

\section{References}

(1) Emily Brown and Paul Cairns : "A Grounded Investigation of Game Immersion”, CHI EA, Vol. 4, pp. 1297-1300, 2004

(2) M. Krijn, P.M.G. Emmelkamp, R.P. Olafsson and R. Biemond : "Virtual reality exposure therapy of anxiety disorders: A review", Clinical Psychology Review, Vol. 24, Issue 3, pp. 259-281, 2004

(3) George Robertson, Mary Czeminski, and Maarten van Dantzich : "Immersion in Desktop Virtual Reality", UIST, Vol. 10, Number, pp. 11-19, 1997

(4) Randy Pausch, Dennis Proffitt and George Williams : "Quantifying Immersion in Virtual Reality", SIGGRAPH, Vol. 24, No. , pp. 13-18, 1997

(5) John R. Wilson, "EFFECTS OF PARTICIPATING IN VIRTUAL ENVIRONMENTSA REVIEW OF CURRENT KNOWLEDGE”, Safety Science, Vol. 23, No. 1, pp. 39-51, 1996

(6) Takayuki Kanda, Hiroshi Ishiguro, Tetsuo Ono, Michita Imai and Ryohei Nakatsu : "An evaluation on interaction between humans and an autonomous robot Robovie", The Robotics Society of Japan, Vol. 20, No. 3, pp. 315323,2002 